\title{
Nutraceutical treatment and prevention of benign prostatic hyperplasia and prostate cancer
}

\author{
Arrigo F.G. Cicero ${ }^{1}$, Olta Allkanjari ${ }^{2}$, Gian Maria Busetto ${ }^{3}$, Tommaso Cai ${ }^{4}$, Gaetano Larganà ${ }^{5}$, \\ Vittorio Magri ${ }^{6}$, Gianpaolo Perletti ${ }^{7}$, Francesco Saverio Robustelli Della Cuna ${ }^{8}$, Giorgio Ivan Russo ${ }^{5}$, \\ Kostantinos Stamatiou ${ }^{9}$, Alberto Trinchieri ${ }^{10}$, Annabella Vitalone ${ }^{2}$ \\ ${ }^{1}$ Dip. di Scienze Mediche e Chirurgiche, Alma Mater Studiorum Università di Bologna, Bologna, Italy; \\ 2 Dipartimento di Farmacologia e Fisiologia "V. Erspamer", Sapienza, Università di Roma, Roma, Italy; \\ ${ }^{3}$ Department of Urology, Sapienza Università di Roma, Policlinico Umberto I, Roma, Italy; \\ ${ }^{4}$ Department of Urology, Santa Chiara Regional Hospital, Trento, Italy; \\ ${ }^{5}$ Urology Department, University of Catania, Catania, Italy; \\ ${ }^{6}$ Ambulatorio Territoriale di Urologia ed Ecografia Urologica, ASST Nord Milano, Milano, Italy; \\ ${ }^{7}$ Dipartimento di Biotecnologie e Scienze della Vita, Sezione di Scienze Mediche e Chirurgiche, Università degli Studi \\ dell'Insubria, Varese, Italy, and Faculty of Medicine and Medical Sciences, Ghent University, Ghent Belgium; \\ ${ }^{8}$ Department of Drugs Sciences, University of Pavia, Pavia, Italy; \\ ${ }^{9}$ Urology Department, Tzaneion Hospital, Piraeus, Greece; \\ ${ }^{10}$ CDC Ambrosiana Milano, Italy.
}

\begin{abstract}
Summary During the last years, pharmaceutical innovations in primary care are dramatically

less frequent and will be even more rare in the next future. In this context, preclinical and clinical research oriented their interest toward natural compounds efficacy and safety, supporting the development of a new "nutraceutical" science. Medicinal plants, in the form of plant parts or extracts of them, are commonly used for the treatment of prostate diseases such as benign hypertrophy, prostatitis and chronic pelvic pain syndrome.
\end{abstract}

The pharmacological properties searched for the treatment of prostatic diseases are anti-androgenic, anti-estrogenic, antiproliferative, antioxidant and anti-inflammatory. The most studied and used medicinal plants are Serenoa repens, Pygeum africanum and Urtica dioica. Other promising plants are Cucurbita pepo, Epilobium spp, Lycopersum esculentum, Secale cereale, Roystonea regia, Vaccinium macrocarpon. In parallel, epidemiological studies demonstrated that diet may play an important role on incidence and development of prostatic diseases. The Mediterranean diet is rich of elements with anti-oxidant properties that act as a protective factor for prostatic cancer. Similarly, low intake of animal protein, high intake of fruits and vegetable, lycopene and zinc are a protective factor for benign prostatic hyperplasia (BPH).

Serenoa repens in the treatment of symptoms of BPH has been tested either alone or, more frequently, in combination with other medicinal plants, alpha-blockers and inhibitors of 5alpha reductase (5-ARI). Recent meta-analyses found the effectiveness of Serenoa repens similar or inferior of that of finasteride and tamsulosin but clearly higher than that of placebo in the treatment of mild and moderate low urinary tract symptoms (LUTS), nocturia and discomfort. Clinical trials showed potential synergistic effect of Serenoa repens with other medicinal plants and drugs. In addition to Serenoa repens, there are many other medicinal plants for which clinical evidence is still controversial. Urtica dioica, Pygeum africanum and Curcubita pepo can be considered as an adjunct to the common therapies and their use is supported by studies showing improvement of symptoms and flowmetric indices. Lycopene and selenium are natural products with antioxidant and anti-inflammatory action. The combination of lycopene and selenium with Serenoa repens was able to reduce inflammation in histological prostate sections and to further improve symptom scores and urinary flow in patients with $\mathrm{BPH}$ on tamsulosin treatment. Similar effects could be obtained with the use of other carotenoids, such as astaxanthin, and/or zinc. Efficacy on symptoms of patients with BPH of some polyphenols such as quercitin, equol and curcumin have been demonstrated by clinical studies. Pollen extract is a mixture of natural components able to inhibit several cytokines and prostaglandin and leukotriene synthesis resulting in a potent anti-inflammatory effect. Pollen extracts significantly improve symptoms, pain, and quality of life in patients affected by chronic pelvic pain syndrome and chronic prostatitis. Beta-sitosterol is a sterol able to improve urinary symptoms and flow measures, but not to reduce the size of the prostate gland.

Palmitoylethanolamide (PEA) is an endogenous fatty acid amide-signaling molecule with anti-inflammatory and neuroprotective effects that can have an interesting role in the management of chronic pelvic pain syndrome and chronic urological pain.

Finally, several plant-based products have been subjected to preclinical, in vitro and in vivo, investigations for their potential pharmacological activity against prostate cancer. Some epidemiological studies or clinical trials evaluated the effects of beverages, extracts or food preparations on the risk of prostate cancer. Some plant species deserved more intense investigation, such as Camelia sinensis (green or black tea), Solanum lycopersicum (common tomato), Punica granatum (pomegranate), Glycine max (common soy) and Linum usitatissimum (linen).

KEY WORDS: Medicinal plant; Prostate; Benign prostatic hyperplasia; Prostate cancer; Antiproliferative effect; $5 \alpha$-reductase; Serenoa repens; Pygeum africanum; Urtica dioica; Cucurbita pepo; Lycopene; Selenium; Polyphenols; Pollen extract; Beta-sitosterol; Palmitoylethanolamide.

Submitted 1 July 2019; Accepted 25 July 2019 


\section{INTRODUCTION TO NUTRACEUTICAL PRESCRIPTION}

(Arrigo F.G. Cicero)

During the last years, the pharmaceutical innovation in primary care are dramatically less frequent and will be even more rare in the next future. In this context, preclinical and clinical research oriented their interest toward natural compounds efficacy and safety, supporting the development of a new nutraceutical science. The term "nutraceutical" has been created by Stephen De Felice in 1989 from the union of the words "nutrition" and "pharmaceutical", to include dietary components or (more generically) botanical bioactive compounds with positive effects on well-being and health preservation, but also for the cure of some common health disorders (1).

The most part of nutraceuticals has been identified in vegetables (2) such as $\beta$-glucans, tocotrienols, plant sterols/stanols, polifenols (anthocyanins, proanthocyanidins, flavonols, stilbens, catechins, epicatechins, cumarins, ellagic acid, isoflavons, lignans, etc.) whose biological activities are numerous and often well-documented. Much less numerous are the nutraceuticals of animal origin, even if some of them, as the omega 3 polyunsaturated fatty acids are among the most used nutraceuticals around the world (4).

There are a large number of medical areas where nutraceuticals are currently used, among them urology and andrology. To warrant the consumer safety and to help the citizens to correctly choose the most adequate nutraceuticals, current laws state that the marketed products should be safe and adequately labelled.

Then, the European Commission promoted specific rules on the nutritional and healthy properties of dietary supplements that can be disclaimed on nutraceutical boxes (Health Claims) (December 20 $\left.{ }^{\text {th }}, 2006\right)(5,6)$.

The European Commission approved health claims are based on the opinions of an external agency, the European Food Safety Authority (EFSA), that periodically should organize meeting of expert panels selected to evaluate and re-evaluate health claims based on the available preclinical and clinical scientific data $(7,8)$.

Currently, the use of dietary supplements and functional foods for the health maintenance and disease prevention is in continuous increase and the number of available products in the market is growng even more intensively. So, how to navigate (as prescribers, sellers or consumers) among 20-30 products containing similar bioactives, in different combinations, that suggest similar effects but with costs often really different? For some of them we have (almost) complete preclinical and clinical pharmaco-toxicological dossiers, till the availability of metaanalysis of randomized clinical trials. However, in the most part of cases, what is known about single bioactives is transferred to the combined marketed products without any kind of test on the final formulation. The main reasons of this are resumed in Table 1 .

In fact, the companies need to market new (at least apparently) "unique" products in a context where the registration and copyright are easily copied and scarcely protected. The cost of the high quality bioactives and the need to create original products often push the industries to add more and more low-dosed components in a single
Table 1.

Factors limiting the application of available scientific data to the combinations of nutraceutical products available in the market.
- No legal need to prove efficacy
- No legal possibility to declare efficacy (lack of approved health claim)
- Incomplete pharmaco-toxicological dossiers
- Cost of high quality bioactives and/or of pharmaceutical technologies used to make them bioavailable (for instance Coenzyme Q10, Resveratrol, Lycopene)
- Industry need to differentiate their product from the other ones
- Need to produce absolutely safe products (often limiting the dosage under the efficacy level)

pill/tablet to make the product more complex ("original") trying to make up eventual synergies, almost never demonstrated. Of course, the use of low-dosed bioactives is a warranty of product safety and tolerability and to avoid the comparison to pharmacological drugs of natural origin, however it reduces the probability to observe a clinical effect. Thus, how to recognize a serious product? As regards monocomponent products, it is relatively easy. The proposed nutraceuticals should have an adequate bibliography support that should include (at least): - The description of the mechanism of action, eventually associated with notes on pharmacokinetic (for instance, resveratrol has an oral bioavailability near to zero, being the supplementation of the raw form of the molecule very doubtful);

- A therapeutic indication supported by randomized, double-blind, placebo-controlled clinical trials carried out on subjects similar to the ones we need to treat in regard to age, ethnicity, and disease profile;

- Quality (bioactive titration) and dosage similar to the one shown to be efficacious and safe in clinical trial.

As regards nutraceuticals in combination, the requirement are similar if the single components are all supported by scientific evidence of efficacy and safety, and if they are included in the same pill/tablet at the tested doses. If a kind of synergy of components is suggested, this has to be clearly demonstrated with specific trials or, alternatively, it should be never mentioned. Of course, the risk of interaction between the components of a combined nutraceutical should also been considered (9).

When the informative brochure of the product is complete and correct, this will help the prescriber to adequately select the more adequate product in the market, being also more protected from a legal point of view (10).

We have to remember that the final responsibility of the prescriber remains in the knowledge to of the effective dosages of the bioactives (based on the results of adequately designed clinical trials or their meta-analysis), of possible pharmacological interaction and adverse events, and of the adequate length of treatment (in particular, avoiding short cyclic treatment for chronic diseases).

\section{Preclinical StUdies ON MEdicinal PLANTS, USED IN THE TREATMENT OF PROSTATIC DISEASES} (Annabella Vitalone, Olta Allkanjari)

Phytotherapy could be useful in the treatment and pre- 
vention of mild to moderate prostatic diseases. The etiology of prostatitis, benign prostatic hyperplasia and hypertrophy $(\mathrm{BPH})$ can be complex and the intervention is often multi-targeted.

The pharmacological properties useful for the treatment of the urinary tract diseases are anti-androgenic, antiestrogenic, anti-proliferative, antioxidant and antiinflammatory.

The most studied and used medicinal plants are: Serenoa repens, Pygeum africanum and Urtica dioica. Phytosterols and fatty acids are the pharmacologically active phytochemicals usually found in these plants; however, they are more used as a phytocomplex (total extract of the plant) than as isolated compounds. In preclinical research, Serenoa is responsible of numerous mechanisms of action, including: inhibition of the dihydrotestosterone binding (DHT) to its receptors present in the cytosol of prostatic cells, of $5 \alpha$-reductase (both isoforms), of cyclooxygenase (COX) and of 5-lipoxygenase (LOX); it induces apoptosis of prostatic epithelial cells and it presents antiestrogenic activity, spasmolytic effect due to blockage of calcium channels and $\beta$-adrenergic antagonism (11). Similar mechanisms have been found for Pygeum and nettle, probably due to the presence of $\beta$-sitosterol and consisting in the inhibition of $5 \alpha$-reductase, of prostatic cell proliferation, blockage of the cell cycle in the G2 phase and induction of apoptosis in prostate cancer cells $(12,13)$. Furthermore, atranorin and atraric acid, present in Pygeum, inhibit the androgen receptor nuclear translocation, endogenous PSA expression, and fibroblast proliferation in human prostate cells. Lignans, lectins and polysaccharides contained in nettle extract, seem to exert anti-proliferative and anti-inflammatory activity, and to inhibit the binding of sex hormones to the sex hormone binding globulin.

Other promising plants are Cucurbita pepo, Epilobium spp (14), Lycopersum esculentum, Secale cereale, Roystonea regia, Vaccinium macrocarpon. They have anti-inflammatory and anti-androgenic properties. In particular, the tomato fruit extract (containing lycopene, polyphenols, etc.) down-regulates $5 \alpha$-reductase and inhibits COX.

The inhibitory properties against $5 \alpha$-reductase appear also for Roystonea regia, probably exerted by the fatty acids. Furthermore, in vitro, antiproliferative, antimicrobial, antioxidant and radical scavenger properties seem encouraging for epilobio, tomato, pollen extracts of Secale cereale and Roystonea regia (15). Vaccinium macrocarpon inhibits aromatase and is helpful in the urinary tract infection, because it acidifies the urine and inhibits bacterial adherence to uroepithelial cells (16). The mechanism of action of the plants listed above has to be confirmed in in vivo models. Other specific plants and/or substances have still limited scientific evidence.

\section{NUtRITIONAL EPIDEMIOLOGICAL STUDIES AND PROSTATE DISEASES}

(Giorgio Ivan Russo, Gaetano Larganà)

Prostatic diseases, like prostatic cancer (PCa) and benign prostatic hyperplasia $(\mathrm{BPH})$, are influenced by different factors, like age, hormone profile and genetics. Several epidemiologic studies demonstrated how diet may play an important role in prostatic diseases incidence and development.

Knowledge of the different kind of effects of foods on prostate could help us to understand how better prevent and treat these diseases, exploiting synergic effects of specific drugs.

PCa represented the most common incident cancer in men in developed countries in 2013 (17).

Western diet, characterized by high intake of energy, red and processed meats and fat but low intake of fibres has been associated to an increased risk to develop an advanced PCa $(18,19)$. Instead, Mediterranean diet $(\mathrm{MeDi})$, that is characterized by use of olive oil and high intake of fibres, fish, fruits, vegetables, legumes and cereals in association with moderate to low intake of dairy products and moderate intake of wine, is a diet rich of components with anti-oxidant proprieties that could protect from PCa (20). In fact, countries following MeDi, particularly Southern European countries, have a lower incidence and mortality from $\mathrm{PCa}$, compared to other European countries $(21,22)$.

A 2015 review included several papers evaluating the effect of single components of MeDi on incidence and development of PCa: olive oil, an unsaturated fat, was not associated with the risk of advanced $\mathrm{PCa}$, that was increased for saturated fat (23-26); in a 2010 metanalysis (27) there was an association between fish consumption and a significant reduction of PCa-specific mortality; higher intake of legumes and cereals has been associated with a decreased risk of several cancer (28), included PCa (29, 30 ); there was a positive association between dairy product consumption and PCa (31); a 2010 review showed how a moderate daily intake of alcohol, 3 drinks per day, does not appear to influence PCa risk (32); lastly Russo et al. showed how consumption of food rich of phenolic acids, like fruits, vegetable, coffee, tea and cacao were associated to a reduced risk of PCa development (33).

$\mathrm{BPH}$ is one of the most common medical conditions in older men (34). A study evaluating more than 3500 patients showed that total protein intake (particularly animal protein) is positively associated with the risk of $\mathrm{BPH}$, while in men who consumed at least 4 servings per day of fruits and vegetable, there was a lower risk of BPH (35-38). Lycopene, contained in tomatoes, seems to help to reduce lower urinary tract symptoms (LUTS) and to inhibits BPH progression, as well as epigallocatechin-3gallate, contained in green tea $(39,40)$. The human prostate gland contains higher level of zinc than other tissues and Kristal et al. (38) showed that zinc could have a protective role for $\mathrm{BPH}$, although excessive consumption may significantly increase the risk of advanced PCa (41-43). Like fot PCa, high alcohol intake may be associated with BPH (44).

In conclusion, epidemiologic studies demonstrated that diet habits could help to prevent PCa and BPH incidence and their development and could be used in a multimodal therapy to prevent and treat these diseases. Particularly, MeDi, a diet rich of elements with anti-oxidant properties related to use of olive oil, high intake of fibres, fish, fruits, vegetables, legumes and cereals, moderate to low intake of dairy products and moderate intake of wine, is a protective factor for PCa. Similarly, 
low intake of animal protein, high intake of fruits and vegetable, lycopene and zinc are a protective factor for $\mathrm{BPH}$. Instead, high intake of saturated fats and animal meat, and excessive alcohol consumption could be a risk for both $\mathrm{PCa}$ and $\mathrm{BPH}$ development.

\section{Clinical use of Serenoa repens in BPH treatment} (Kostantinos Stamatiou)

A variety of phytotherapeutic agents are used in traditional and alternative medicine to treat lower urinary tract symptoms. The most commonly used preparations originate from the species Saw palmetto. Their extract Serenoa repens (SR) exhibits marked anti-inflammatory, anti-androgenic and anti-proliferative effects. For this reason, it has been the subject of clinical and experimental research on the treatment of symptoms of benign prostatic hyperplasia.

A non-systematic search was performed in electronic libraries for clinical trials, experimental studies and systematic reviews on the topic. Main outcomes of the abovementioned studies are displayed in Table 2.

SR in the treatment of symptoms of BPH has been tested either alone or, more frequently, in combination or in comparison with other phytotherapeutics, alpha-blockers and inhibitors of 5- $\alpha$ reductase (5-ARI).

With regard to studies using SR extract as monotherapy for men with BPH an confirmed lower urinary tract symptoms (LUTS), Lopatkin et al. and Giulianelli et al. showed significant improvement in symptom scores (IPSS ans IIEF-5) and uroflowmetry at 6-month follow up $(45,46)$. Accordingly, Sinescu et al. (47) demonstrated a significant improvement of mild or moderate LUTS, quality of life (QoL), urinary flow, residual urinary volume and erectile function and Gerber et al. demonstrated improvement in urinary symptoms compared with placebo (but no measurable effect on urinary flow) (48). On the contrary, the large trial of CAMUS Study Group found no differences between improvements of urinary symptoms between SR extract and placebo group at 72-week follow-up (49) in accordance to other placebo-controlled trials $(50,51)$. Recently, Ye et al. (52) in a double blind, placebo-controlled study found significant improvements in the urinary flow, IPSS, male sexual function (MSF-4 and IIEF scores) in the SR extract group. In none of these studies significant side effects of SR were observed. Higher doses of SR cannot influence neither the impact on LUTS nor the quality of sexual performance $(53,54)$.

Efficacy of SR was compared to other treatments. Alcaraz et al. (55) found equivalent efficacy with respect to alpha-blockers and 5-ARI in LUTS improvement; Pytel et al. $(56,57)$ confirmed similar results as measured by IPSS, QoL, index of sexual function (MSF-4), size of the prostate, urodynamic parameters (but no change of plasma sexual hormones). A prospective multicentre doubleblind randomized study comparing tamsulosin (0.4 $\mathrm{mg} / 24 \mathrm{~h}$ ) with SR (320 mg/24h) found no differences in IPSS, urinary flow and PSA at 12-month follow up (58). SR was used in combination with other treatment. The addition of dietary supplements or other phytotherapeutic agents improved the effect of SR $(59,60)$. The combination of SR with alpha-blockers agents (tamsulosin, silodosin) was more effective than monotherapy according to some Authors $(61,62)$ although others were not able to demonstrate no extra benefits by combination therapy (63-68).

Recent meta-analyses found the effectiveness of SR similar or inferior of that of finasteride and tamsulosin but clearly higher than that of placebo in the treatment of mild and moderate LUTS, nocturia and discomfort (69-71).

The ability of SR to reduce prostatic size is controversial, although the association with other natural compounds (such as lycopene, other carotenoids and selenium) could enhance the activity of SR alone by augmenting pro-apoptotic effects and suppressing growth factors expression in hyperplastic prostates (72). The evaluation of the results of BPH treatment with SR is made difficult by the variability of the composition of products of different brands in relation the concentration of free fatty acids and the method of extract preparation.

Table 2.

Design of studies of Serenoa repens for BPH treatment.

\begin{tabular}{|c|c|c|c|c|c|c|c|c|}
\hline & Placebo & SR & 5ARI & $\begin{array}{c}\text { Alpha- } \\
\text { blockers }\end{array}$ & $\begin{array}{l}\text { Pinus }+ \\
\text { Crocus } \\
+ \text { SR }\end{array}$ & $\begin{array}{c}S R+L Y+ \\
+S E\end{array}$ & $\begin{array}{c}\text { Alpha- } \\
\text { blocker } \\
\text { SR+LY+ } \\
\text { SE }\end{array}$ & $\begin{array}{c}\text { Alpha- } \\
\text { blocker } \\
\text { SR }\end{array}$ \\
\hline Dedhia (50) & + & + & & & & & & \\
\hline Bent (51) & + & + & & & & & & \\
\hline Ye (52) & + & ++ & & & & & & \\
\hline Barry (53) & + & + & & & & & & \\
\hline Alcaraz (55) & & + & + & + & & & & \\
\hline Debruyne (58) & & + & & + & & & & \\
\hline Cai (59) & & + & & & ++ & & & \\
\hline Morgia (60) & & + & & & & ++ & & \\
\hline Morgia (61) & & & & + & & + & ++ & \\
\hline Ryu (63) & & & & + & & & & ++ \\
\hline Boeri (62) & & + & & + & & & & ++ \\
\hline Argirovic (64) & & + & & + & & & & + \\
\hline Bertaccini (67) & & + & & & & & & + \\
\hline Gerber (48) & + & ++ & & & & & & \\
\hline Helfand (49) & + & + & & & & & & \\
\hline Glemain (65) & & + & & + & & & & + \\
\hline Hizli \& Uygur (66) & & + & & + & & & & + \\
\hline
\end{tabular}

\section{Clinical use of other medicinal plants for BPH treatment: Urtica dioica, Pygeum AFRICANUM E CUCURBITA PEPO}

(Gian Maria Busetto)

Alongside the traditional $5 \alpha$-reductase and $\beta$-blockers, medical therapy for LUTS secondary to BPH, is based on nutraceuticals and compounds. In addition to Serenoa repens, which has been extensively studied, there are many other substances for which scientific evidence is often controversial.

Urtica dioica has the capability to decrease testosterone conversion to dyhdrotestosterone (DHT), interact with sex hormone-binding globulin (SHBG) and block the conversion of androgens to estrogens. Other studies report even an antiproliferative action on prostate cancer cells.

Pygeum africanum is rich in phytosterols and antioxidants. An inhibitory effect on prostate growth factors, on androgenic hormones and an effect on the contractility of 
Table 3.

Symptoms, IPSS and flowmetric indices after treatment with Urtica dioica, Pygeum africanum and Cucurbita pepo.

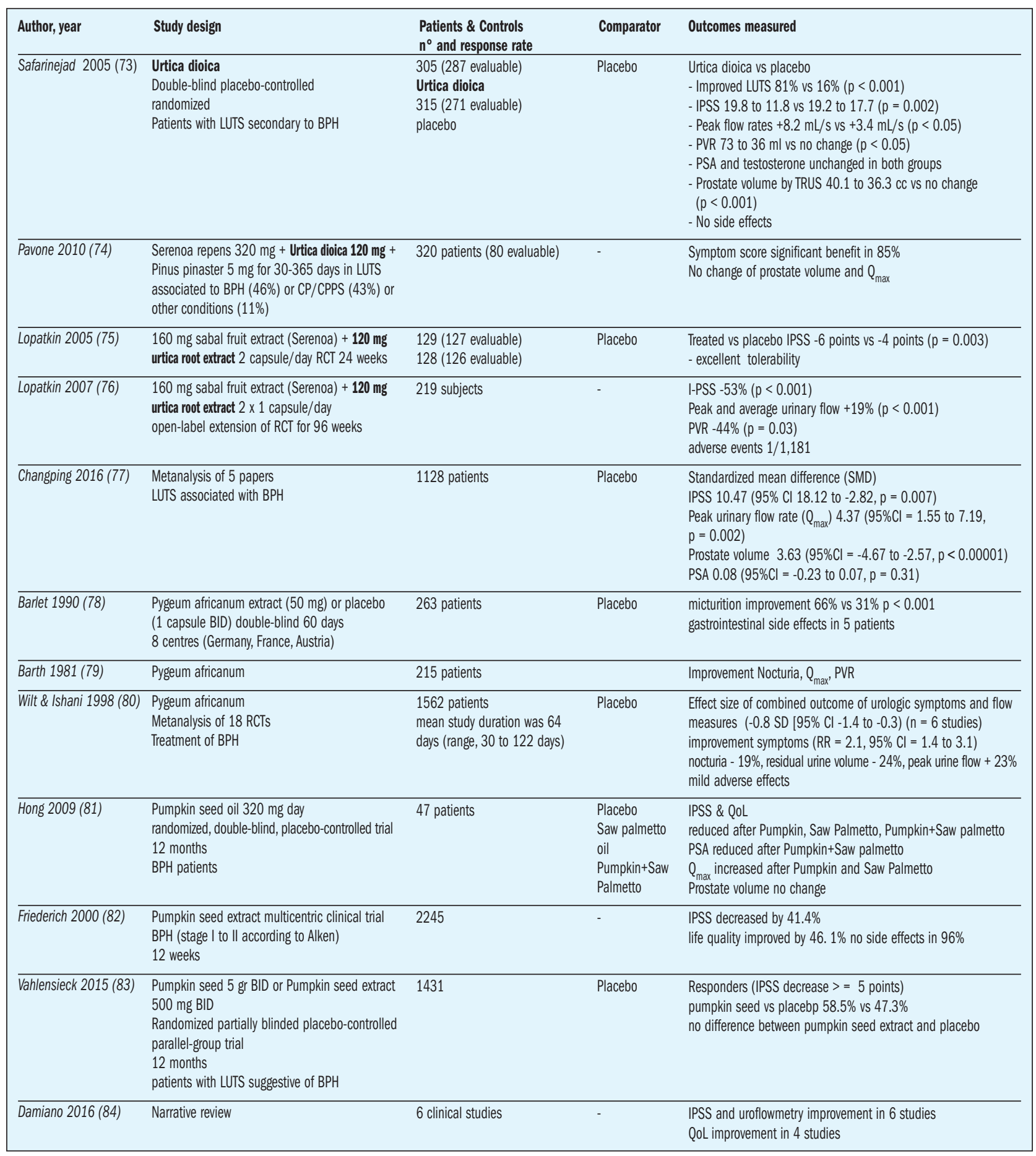

the detrusor musculature of the bladder have been hypothesized. Some authors have also reported an improvement in the parameters of the semen, in particular on sperm motility. Curcubita pepo mainly contain fatty acids, specific sterols, tocopherol, carotenoids, vitamins and micronutrients. It is mainly the high $\Delta$-7-sterol content that has the therapeutic effect and that has been shown to reduce prostate volume in the main animal models.
These treatments can be considered as an adjunct to the common therapies and their effect is supported by improving symptoms, IPSS and flowmetric indices (Table 3) (73-84). Their action on the volume of the prostate gland and on inflammation is more controversial. The literature is lacking data and double-blind placebo-controlled studies able to improve levels of evidence. It is therefore necessary to continue studying these substances, commissioning adequate trials with 
high statistical power, strict inclusion and exclusion criteria and with adequate case studies.

\section{Carotenoids and mineral supplements}

(Vittorio Magri)

Lycopene and selenium are two natural products with antioxidant and anti-inflammatory action. Lycopenes are carotenoids, natural pigments widely distributed in the environment that are synthesized both by plants and bacteria, but not by the animals that must take them with the diet. Lycopene accumulates in the prostate and is secreted in the seminal fluid. Dietary supplementation of rats resulted in accumulation of lycopene in all prostatic lobes, but preferentially in the lateral lobes. Lycopene concentrations are gradually increased and interfered with local prostate androgenic signaling, IGF-1 expression, and inflammatory mediators $(85,86)$. Selenium has an essential role in some enzymatic activities such as glutathione-peroxidases (87, 88) that can reduce hydrogen peroxide, and lipid and phospholipid hydroperoxides, counteracting free radical damage and oxygen-reactive species (ROS). Furthermore, selenium is important for maintaining an efficient immune response $(89,90)$. Studies in vitro and on animal models, have shown that Serenoa repens-Selenium-Lycopene (SeR-SeLy) administered in combination, are synergistic and amplify their action both on the inflammatory and proliferative component (91-93). Some clinical studies have confirmed the efficacy of the SR-Se-Ly association in patients with BPH. In the FLOG study the administration of SR-Se-Ly in patients who had to undergo prostatic rebiopsy due to suspected prostate cancer showed a significant reduction in inflammation and the number of lymphocytes and macrophages in histological sections (94).

In the PROCOMB study (61), patients treated with SR-Se$\mathrm{Ly}+$ tamsulosin had a greater reduction in the IPSS score, an increase in $\mathrm{Q}_{\max }$ and a reduction in the post-voiding urinary volume, compared to those treated with tamsulosin alone. A randomized double-blind study of patients with $\mathrm{BPH}$ treated with an herbal mixture that also contains lycopene showed a significant reduction in the total IPSS score, pollakiuria and nocturia in treated patients (95).

Similar effects to those obtained with lycopene and selenium could be obtained with the use of other carotenoids and/or zinc. Astaxanthin, at low concentration, was able to inhibit in vitro $5 \alpha$-reductase by $98 \%$ and to decrease growth of cultured prostate cancer cell lines (96). The accumulation of zinc in prostate tissue depends, more than on dietary intake, on the activity of specific transporters (ZnT4 and ZIP4) that can be modulated by natural products as diadzein and genistein (97, 98). In patients with symptomatic BPH a combination of zinc, daidzein and Isolase (a mixture of enzymes that increases the bioavailability of plant polyphenols) improved at 6-month follow up IPSS score, peak urinary flow rate and quality of life (99).

The close correlation between prostatic inflammation and LUTS associated to BPH, as demonstrated by MTOPS and REDUCE clinical studies $(100,101)$, suggests a new systematic approach to the medical therapy of symptomatic $\mathrm{BPH}$ based on the association of a drug with anti-inflammatory activity to alpha-blockers and/or 5ARI drugs. Considering the side effects of non-steroidal anti-inflamma- tory drugs (NSAID), the use of natural substances with a low risk of complications is attractive. Further studies are needed to evaluate the short and long-term efficacy of this approach to validate its use in the daily clinical practice for treatment of benign prostate diseases.

\section{Polyphenols}

\section{(Alberto Trinchieri)}

Polyphenols are a large class of organic chemicals (> 8000) characterized by the presence of large multiples of phenols structural units. They can be differentiated according to the chemical structure of the polyphenol skeleton. Flavonoids, lignins, phenolic acids, stilbenes and other polyphenols belong to this class (Table 4). Polyphenols can act on prostatic hyperplasia with different mechanisms: inhibition of $5 \alpha$-reductase; decreased expression of growth factors (IGF-I and IGF-II); anti-inflammatory action (reduction of interleukin levels IL 1- $\beta$, IL 6, IL-I6 and tumor necrosis factor TNF- $\alpha$, inhibition of COX-2 and 5-lipogenase, increased synthesis of nitric oxide and expression of nitric oxide synthase ); induction of apoptotic activity (increased expression of pro-apoptotic caspase-3 protein, up-regulation of peroxisomal proliferation receptors PPAR $\alpha$ and $\gamma$, increased expression of G protein estrogen receptor 1 coupled GPER); increased antioxidant activity (superoxide dismutase, glutathione peroxidase). Experimental evidences based on in vitro studies on homogenates of hyperplastic prostate cells or prostatic cell lines demonstrated prevalent inhibitory effect of $5 \alpha$ reductase type 2 of isoflavones (phytoestrogens), while flavonols and flavones show inhibitory effect of $5 \alpha$-reductase type 1 but also anti-inflammatory ant antioxidant effects and induction of apoptosis (102, 103). Phenolic acids and lignins also have a combined action on $5 \alpha$ reductase and induction of apoptosis (104). In experimental models of BPH in rats, the efficacy of cocoa extract, soy-derived isoflavones, quercitin, a mixture of baicalin and catechin (flavocoxid), equol, anthocyanins derived from black soy, flavonoids extracted from Garcinia kola (kolaviron), epigallocatechin-3-gallate, secoisolariciresinol and curcumin was demonstrated (105-115). Clinical studies in patients with BPH have demonstrated the efficacy of quercitin, a flavonol contained in various foods such as onions, citrus fruits, cranberry, spices, tea and red wine (116), of equol (a metabolite of daidzein which is a soy isoflavon) (117), a flaxseed extract containing the lignin secoiso-lariciresinol diglucoside (SDG) (118) and of curcumin, a derivative of the spice Curcuma longa (119). Conversely, resveratrol has not been shown to be effective in reducing prostate volume and levels of testosterone, didrotestosterone (DHT) and PSA (120). Different types of polyphenols are contained in medicinal plants that have been used in the treatment of IPB, such as epliobium (121) and extract from the bark of French maritime pine (122).

\section{Pollen extract, Beta-sitosterol and Palmitoylethanolamide (PEA)}

(Tommaso Cai)

Pollen extract is a mixture of natural components, such as amino acids, carbohydrates, lipids, vitamins, phytos- 
Table 4.

Classification, sources, biological and clinical activity of polyphenols used for BPH treatment.

\begin{tabular}{|c|c|c|c|c|c|c|}
\hline \multirow{2}{*}{$\begin{array}{l}\text { Classification } \\
\text { FLAVONOIDS }\end{array}$} & Name & Source & In vitro 5-AR & In vitro other effects & Animal models & Clinical studes \\
\hline & \multicolumn{6}{|c|}{ C6-C3-C6 general structural backbone with two C6 units of phenolic nature } \\
\hline \multirow[t]{3}{*}{ Flavonols } & Quercitin & $\begin{array}{l}\text { onions } \\
\text { citrus } \\
\text { cranberry } \\
\text { spices } \\
\text { tea } \\
\text { red wine }\end{array}$ & $\begin{array}{l}\text { 5-AR type } 1 \text { inhibition } \\
\text { (?) } \\
\text { Decreased DHT } \\
\text { by androgen-inde- } \\
\text { pendent effect } \\
\text { SHBG }\end{array}$ & $\begin{array}{l}\text { Antinflammatory } \\
\text { (decrease cytochines, sup- } \\
\text { pressed TNF-alfa and MCP-1 } \\
\text { expression by NF-kappa B } \\
\text { inhibition) } \\
\text { Antioxidant } \\
\text { Proapoptotic (TGF increase) }\end{array}$ & Decreased prostate volume & $\begin{array}{l}\text { IPSS decreased } \\
Q_{\max } \text { increased }\end{array}$ \\
\hline & Mirecitin & red wine & 5-AR type 1 inhibition & - & No & \\
\hline & Fisetin & $\begin{array}{l}\text { strawberry } \\
\text { apples } \\
\text { grapes }\end{array}$ & 5-AR type 1 inhibition & - & No & \\
\hline Flavanons & $\begin{array}{l}\text { GB1 e GB2 } \\
\text { kolaflavonone binaringen- } \\
\text { ina (Kolaviron) }\end{array}$ & Garcinia kola & - & Antioxidant & Decreased prostate volume & \\
\hline Flavan-3-ols & Epigallocatechin-gallate & Green tea & & $\begin{array}{l}\text { Antinflammatory } \\
\text { (decreased IL-I } \beta \text {, IL-I6, and TNF- } \\
\alpha \text { ) Antioxidant } \\
\text { Decreased IGF-I e IGF-II } \\
\text { Proapoptotic PPAR- } \alpha \text { e PPAR- } \gamma \\
\text { up-regulation }\end{array}$ & Decreased prostate volume & \\
\hline \multirow[t]{2}{*}{ Flavones } & Baicalin & $\begin{array}{l}\text { Scutellaria baicalensis and } \\
\text { Scutellaria lateriflora }\end{array}$ & 5-AR type 1 inhibition & $\begin{array}{l}\text { Antinflammatory } \\
\text { (inhibition cicloxigenase } 2 \text { and } \\
\text { 5-lipooxigenase } \\
\text { Decrease growth factors }\end{array}$ & $\begin{array}{l}\text { Decreased prostate volume } \\
\text { by a mixture of baicalin and } \\
\text { catechin (flavocoxid), }\end{array}$ & \\
\hline & Kaempferol & $\begin{array}{l}\text { Apples } \\
\text { broccoli, onions, tomatoes }\end{array}$ & 5-AR type 1 inhibition & & No & \\
\hline Anthocyanidins & Antocianin & Black soy & & Proapoptotic & Decreased prostate volume & \\
\hline \multirow{5}{*}{$\begin{array}{l}\text { Isoflavones } \\
\text { (phytoestrogens) }\end{array}$} & Daidzein & Soy & 5-AR type 2 inhibition & & Decreased prostate volume & \\
\hline & Genistein & & 5-AR type 2 inhibition & & by soy-derived isoflavones & \\
\hline & & Fava beans & & & & IPSS decrease \\
\hline & Biocanin A & Soy Peanuts & 5-AR type 2 inhibition & & & \\
\hline & Equol & Soy & 5-AR type 2 inhibition & & Decreased prostate volume & Decrease \\
\hline \multirow[t]{2}{*}{ STILBENS } & \multicolumn{6}{|c|}{ Hydroxylated derivatives of stilbene with C6-C2-C6 structure } \\
\hline & Resveratrol & $\begin{array}{l}\text { Grapes } \\
\text { Red wine }\end{array}$ & & & & $\begin{array}{l}\text { No decrease } \\
\text { prostate volume } \\
\text { No effect on } \\
\text { testosterone and } \\
\text { DHT }\end{array}$ \\
\hline \multirow[t]{3}{*}{ LIGNANS } & \multicolumn{3}{|c|}{ Two units of a phenylpropene derivative } & & & \\
\hline & $\begin{array}{l}\text { Secoisolarici-resinol } \\
\text { diglucoside }\end{array}$ & Flaxseed & & $\begin{array}{l}\text { Proapoptotic } \\
\text { Increased GPER expression }\end{array}$ & Decreased prostate volume & \\
\hline & Enterolactone & $\begin{array}{l}\text { Sesame } \\
\text { Flaxseed }\end{array}$ & 5-AR type 2 inhibition & & No & \\
\hline \multirow[t]{2}{*}{ FENOLIC ACIDS } & \multicolumn{3}{|c|}{ Phenolic ring and an organic carboxylic acid function (C6-C1 skeleton) } & & No & \\
\hline & $\begin{array}{l}\text { Caffeic Acid Phenethyl } \\
\text { Ester (CAPE) }\end{array}$ & Propoli & 5-AR type 2 inhibition & & & \\
\hline OTHER POLYFENOLS & Curcumin & Curcuma lunga (spice) & & $\begin{array}{l}\text { Decreased growth factors (VEGF, } \\
\text { TGF-ß1, and IGF1). }\end{array}$ & Decreased prostate volume & IPSS decrease \\
\hline
\end{tabular}

terols and minerals (123). The compound of the pollen extract is able to inhibit several cytokines, such as prostaglandin and leukotriene synthesis and this effect is comparable to that of diclofenac and indomethacin and approximately 10 times higher than that of aspirin (124). The pharmacological effects are due to the inhibiting activity of carvacrol, a pollen extract component, on the NF-KB (Nuclerar Factor Kappa Light Chain Enhancer of Activated $B$ Cells). The inhibition of NF-KB reduce the levels of prostaglandin E2 and increase the production of beta-endorphins with inflammation decrease and pain relief (125). Moreover, several authors demonstrated that pollen extract has a possible pro-apoptotic effect on the prostate via the androgen metabolism. In particular, it protects acinar prostate epithelial cells and inhibits stromal proliferation in association with enhanced apoptosis. Finally, several in vitro studies demonstrated that pollen extract is able to inhibit the prostate cancer cell growth 
Table 5.

Pre-clinical and clinical trials about the use of pollen-extract.

\begin{tabular}{|c|c|c|c|c|}
\hline Author, year & Study design & $\begin{array}{l}\text { Patients \& controls } \\
\mathrm{n}^{\circ} \text { and response rate }\end{array}$ & Comparator & Outcomes measured \\
\hline Buck AC, 1989 (132) & Prospective trial (phase II) & $15(86.6)$ & & $\begin{array}{l}\text { Pollen extract effective in the treatment of chronic prostatitis and } \\
\text { prostatodynia }\end{array}$ \\
\hline Cai T, 2013 (133) & Prospective trial (phase II) & $20(90.0)$ & & $\begin{array}{l}\text { Pollen extract significantly improved total symptoms, pain, and } \\
\text { QoL in patients with non-inflammatory CP/CPPS without severe } \\
\text { side effects }\end{array}$ \\
\hline Cai T, 2014 (134) & Randomized controlled trial & $\begin{array}{l}41(75.6) \\
46(41.3)\end{array}$ & Ibuprofen & $\begin{array}{l}\text { Pollen extract significantly improved quality of life of patients } \\
\text { when compared with those treated with ibuprofen (treatment } \\
\text { difference in the NIH-CPSI pain domain, }-2.14 \pm 0.51 \text {, } \\
p<0.001 \text {; QoL scores, } p=0.002 \text { ) }\end{array}$ \\
\hline Elist J, 2006 (135) & Randomized controlled trial & $\begin{array}{l}30(73.3) \\
28(64.2)\end{array}$ & Placebo & $\begin{array}{l}\text { Pollen extract is superior to placebo in providing symptomatic } \\
\text { relief in men with chronic nonbacterial prostatitis/chronic pelvic } \\
\text { pain syndrome }\end{array}$ \\
\hline Iwamura H, 2015 (136) & Randomized placebo-controlled trial & $\begin{array}{l}50(78.1) \\
50(88.2)\end{array}$ & $\begin{array}{l}\text { Eviprostat } \\
\text { (phyto-thera- } \\
\text { peutic agent) }\end{array}$ & $\begin{array}{l}\text { Pollen extract significantly reduced the symptoms of category III } \\
\text { CP/CPPS without any adverse events, in terms of NIH-CPSI, } \\
\text { IPSS, and QoL }\end{array}$ \\
\hline Jodai A, 1988 (137) & Prospective trial (phase II) & $32(75.0)$ & & $\begin{array}{l}\text { Pollen extract significantly reduced the symptoms in } 75.0 \% \text { of } \\
\text { all treated patients }\end{array}$ \\
\hline Monden K, 2002 (138) & Prospective trial (phase II) & $24(91.6)$ & & $\begin{array}{l}\text { Pollen extract significantly reduced the symptoms of chronic } \\
\text { prostatitis group }\end{array}$ \\
\hline Ruǵendorff EW, 1993 (139) & Prospective trial (phase II) & $90(62.2)$ & & $\begin{array}{l}\text { Pollen extract significantly reduced the symptoms of category III } \\
\text { CP/CPPS without any adverse events, in terms of urinary } \\
\text { symptoms and QoL }\end{array}$ \\
\hline Suzuki T, 1992 (140) & Prospective trial (phase II) & $25(96.0)$ & & $\begin{array}{l}\text { Pollen extract significantly reduced the symptoms of prostatitis } \\
\text { patients without any adverse events }\end{array}$ \\
\hline
\end{tabular}

and this effect is even more pronounced in the hormoneindependent models, suggesting that there might be a place for the pollen extract in the control of abnormal growth in hormone-insensitive cells (126-130).

On the clinical point of view, pollen extracts significantly improve symptoms, pain, and quality of life in patients affected by chronic pelvic pain syndrome and chronic prostatitis. These evidences have been done by a recent systematic review and meta-analysis (131) of 4 RCTs, that demonstrated that the use of flower pollen extracts in the management of CP/CPPS patients is associated with a high rate of clinical response without any significant adverse events. The Table 5 of all pre-clinical and clinical trials about the use of pollen-extract. No side effects are reported in all clinical trials (132-141).

Beta-sitosterol is a sterol commonly present in the almost all plants, such as rice bran, wheat germ, peanuts, corn oils, soybeans, saw palmetto, rye grass pollen and pygeum. Its activity is due to the fact that cannot be converted to testosterone and inhibits aromatase and $5 \alpha$ reductase (142). Due to these pharmacological properties, beta-sitosterol is able to improve urinary symptoms and flow measures, as demonstrated by a Cochrane Review (143). On the other hand, beta-sitosterol is not able to reduce the size of the prostate gland. In general, no adverse effects are reported during therapy, even if gastrointestinal side effects are the most common. However, we need consider that this compound can enhance the cholesterol-lowering effects of antihyperlipidemic medications.

Palmitoylethanolamide (PEA), an endogenous fatty acid amide-signaling molecule has well-known anti-inflammatory and neuroprotective effects. The clinical antiinflammatory effect is due to the downregulation of mediator release from mast cells, monocytes and macrophages. In particular, in recent experience, PEA seems to have interesting activities in regulation of neurogenic and neuropathic pain. It has been demonstrated that PEA is able to act on TRPV1 channels, by indirect activity and desensitization. Several authors showed an interesting role in the management of chronic pelvic pain syndrome and chronic urological pain (144-146).

\section{Medicinal Plants fOR PREVEntion AND TREATMENT OF PROSTATIC CARCINOMA}

(Gianpaolo Perletti)

Medicinal plants and herbal products, in the form of plant parts or extracts of them, are commonly used for the treatment of prostate diseases such as benign hypertrophy, prostatitis and chronic pelvic pain syndrome. Over the past 20 years, dozens of plant-based products 
have been subjected to preclinical in vitro and in vivo investigations for their potential pharmacological activity against prostate cancer $(\mathrm{PCa})$. Less numerous but worthy of special attention are epidemiological studies or clinical trials in which plant species, administered in the form of beverages, extracts or food preparations, have been studied for their effect on prostate cancer. Here follows an example of plant species which have been subjected to deeper investigation.

Camelia sinensis (CS), in the form of unfermented (green) or fermented (black) tea, is rich in polyphenols, the most representative and investigated being epigallocatechin-3gallate (EGCG; green tea contains about 10-fold ECGC compared to black tea). A number of epidemiological and clinical studies have attempted to investigate the preventive effect of CS intake on prostate cancer. Such studies have been pooled in at least 6 meta-analyses, among which the work of Fei et al. (147), including 29 data series, appears to be the most comprehensive.

We deemed interesting to integrate such meta-analysis with the more recent studies of Lassed et al. (280 patients, risk ratio $=0.51 ; 95 \%$ CI: 0.14-1.82) and Sen et al., (142, 196 men, of which 7036 PCa cases; risk ratio: 1.06; 95\% CI: 0.98-1.14) (148, 149). Our metanalysis (Figure 1) (150) shows that, in contrast to the significant data of Fei and coworkers (147), (risk ratio $=0.84 ; 95 \%$ CI: 0.71-0.98), the addition of the Lassed and Sen (148, 149 ) trials results in a non-significant pooled risk ratio (0.89; 95\% CI: 0.77-1.02). The publication bias for this pooled analysis is not significant (Egger's test: $p=0.542$; Begg\&Mazumdar's test: $\mathrm{p}=0.311$ ), but the analysis shows substantial heterogeneity $(\mathrm{I} 2=0.69)$.

More focused analyses, investigating the effect of high doses of green tea catechins, tested in the frame of randomized-controlled studies, resulted in a significant protective effect against PCa.

Thus, whereas studies about consumption of CS infusions in the general population have given contradictory results - probably also due to uncertain dosage, length of therapy, herb quality, patient compliance, etc. -, rigorous, controlled clinical trials seem to provide encouraging evidence about the antitumor activity of CS catechins.

Solanum lycopersicum, the common tomato, contains high quantities of lycopene, a carotenoid antioxydant hydrocarbon (C4OH56) devoid of vitamin-A activity. Lycopene, investigated in the frame of meta-analyses of epidemiological studies, doesn't seem to show a significant PCa preventive activity $(151,152)$. However, single studies suggest that lycopene shows indeed protective activity (153), and can as well lower PSA levels in prostate cancer

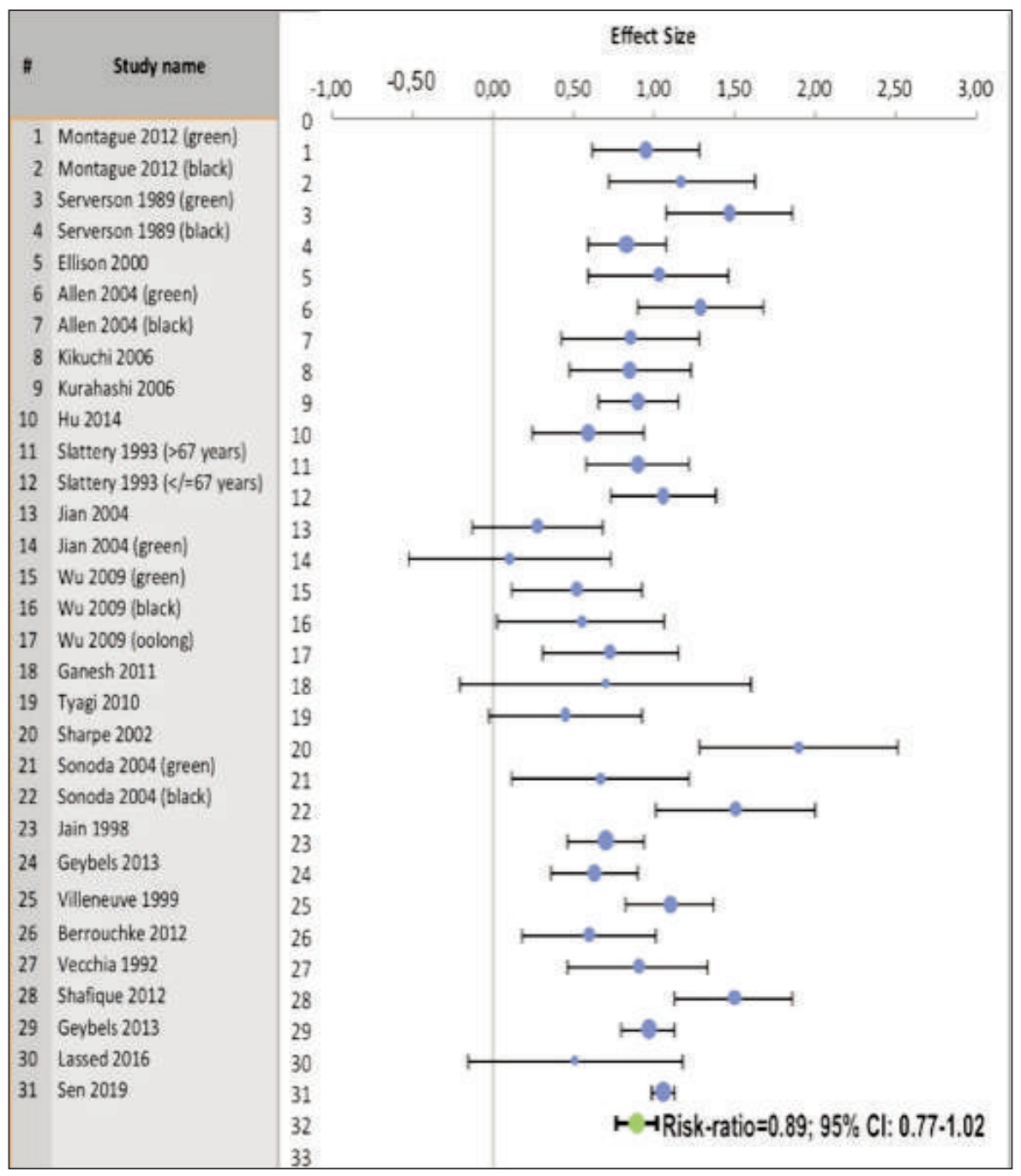

Figure 1.

Forest plot.

Risk-ratio for the association between the consumption of various preparations of tea (beverage, concentrates, etc.) and prostate cancer, assessed by pooling 23 epidemiological studies (31 data series). The values at the right of the no-effect unit $(n=1)$ show an increased relative risk for prostate cancer, whereas data plotted on the left show a protective effect of tea intake against prostate cancer. Arch Ital Urol Androl, this issue.

Random effect model, MantelHaenszel statistics, MetaEssentials software. 
patients (154). Punica granatum, pomegranate (PG), contains a number of active polyphenol compounds (e.g., elagitannins) and fatty acids (punicic acid). Promising preclinical results have not been translated so far into sound clinical evidence. Whereas in earlier clinical studies PG seemed to significantly prolong the PSA doubling time in patients with localized PCa (155), recent placebo-controlled trials failed to show increased PSA doubling times by PG preparations, compared to placebo $(156,157)$.

Glycine max, the common soy, and Linum usitatissimum, known as flax or lineseed, contain isoflavones (e.g., genistein) and lignans which are known to act as phytoestrogens. These compounds, which have been hypothesized to be active against PCa growth, have been tested in the frame of clinical trials in PCa patients. It is not clear whether soy extracts show any effect on PCa and PSA, as clinical data produced so far didn't show univocal therapeutic effects $(158,159)$. Similarly, single clinical trials and meta-analyses suggest that flax lignans do not seem to have a significant therapeutic activity (160). However, a metanalysis of observational studies by He and coworkers has evidenced a significant association between high serum levels of the lignan metabolite enterolactone and a reduced odds of prostate cancer (OR $=0.76,95 \%$ CI: 0.60-0.97) (He et al.).

In conclusion, Camelia Sinensis catechins, Solanum lycopersicum lycopene and the flax lignan metabolite enterolactone have shown some chemopreventive or therapeutic activity against PCa. The major limitation of the clinical studies and meta-analyses produced so far is the great variability of key elements such as (i) compound quality (poor standardization), (ii) patient compliance (virtually unknown in observational studies), (iii) active drug dosages (extremely diverse according to dietary customs worldwide), and (iv) preparation modalities. Randomized controlled trials versus placebo or versus compounds of established efficacy are still scant. To draw any final conclusion concerning the efficacy of medicinal plants and fruits for preventing or treating PCa, additional well-designed, adequately powered clinical trials are urgently needed.

\section{REFERENCES}

1. Sirtori CR, Arnoldi A. Introduzione. In: Borghi C, Cicero AFG "Nutraceutici ed alimenti funzionali in medicina preventiva". Bononia University Press, Bologna, 2011; pp. 9-16.

2. Bidlack WR, Omaye, ST, Meskin MS, Topham DKW. Phytochemicals as bioactive agents. CRC press. UK, 2016.

3. Woo HD, Kim J. Dietary flavonoid intake and smoking-related cancer risk: a meta-analysis. PLoS One. 2013; 8:e75604.

4. Cicero AF, Ertek S, Borghi C. Omega-3 polyunsaturated fatty acids: their potential role in blood pressure prevention and management. Curr Vasc Pharmacol. 2009; 7:330-7.

5. Gulati OP, Berry Ottaway P. Legislation relating to nutraceuticals in the European Union with a particular focus on botanical-sourced products. Toxicology 2006; 221:75-87.

6. Liuzzo G, Bentley S, Maggi E. Food safety and risk communication. Industrie Alimentari. 2001; 497-503.

7. Roe B, Levy A, Derby B. The impact of health claims on consumer search and product evaluation outcomes: results from FDA experimental data. J Public Policy Mark. 1999; 18: 89-105.
8. Prasad C, Cicero AF, Petrini O. Planning meaningful clinical trials with botanicals and nutraceuticals: need for a cross-talk between science, business and the regulatory demand. Curr Top Nutraceut $R$. 2017; 15:49-56.

9. Cicero AF, Petrini O, Prasad C. Clinical studies with nutraceuticals and how to carry them out. Curr Top Nutraceut R. 2017; 15:63-66.

10. Cicero AFG, Borghi C. Come riconoscere un nutraceutico commerciale "serio": alcuni suggerimenti. In: Borghi C, Cicero AFG "Nutraceutici ed alimenti funzionali in medicina preventiva". Bononia University Press, Bologna. 2011; pp. 463-466.

11. Governa P, Giachetti D, Biagi M, et al. Hypothesis on Serenoa repens (Bartram) small extract inhibition of prostatic $5 \alpha$-reductase through an in silico approach on $5 \alpha$-reductase $x$-ray structure. Peer J. 2016; 4:e2698.

12. Jena AK, Vasisht K, Sharma N, et al. Amelioration of testosterone induced benign prostatic hyperplasia by Prunus species. J Ethnopharmacol. 2016; 190:33-45.

13. Mohammadi A, Mansoori B, Aghapour M, Baradaran B. Urtica dioica dichloromethane extract induce apoptosis from intrinsic pathway on human prostate cancer cells (PC3). Cell Mol Biol. 2016; 62:78-83.

14. Vitalone A, Allkanjari O. Epilobium spp: pharmacology and phytochemistry. Phytother Res. 2018; 32:1229-40.

15. Allkanjari $O$, Vitalone A. What do we know about phytotherapy of benign prostatic hyperplasia? Life Sci. 2015; 126:42-56.

16. Guay DR. Cranberry and urinary tract infections. Drugs. 2009; 69:775-807.

17. Dy GW, Gore JL, Forouzanfar MH, et al. Global Burden of Urologic Cancers, 1990-2013. Eur Urol. 2017; 71:437-446.

18. Ambrosini GL, Fritschi L, de Klerk NH, et al. Dietary Patterns Identified Using Factor Analysis and Prostate Cancer Risk: A Case Control Study in Western Australia. Ann Epidemiol 2008. Ann Epidemiol. 2008; 18:364-70.

19. Stefani E De, Deneo-Pellegrini H, Boffetta P, et al. Dietary patterns and risk of cancer: A factor analysis in Uruguay. Int J Cancer. 2009; 124:1391-7.

20. Sofi F, Macchi C, Abbate R, et al. Mediterranean diet and health. Biofactors. 2013; 39:335-42.

21. Bray F, Lortet-Tieulent J, Ferlay J, et al. Prostate cancer incidence and mortality trends in 37 European countries: An overview. Eur J Cancer. 2010; 46:3040-52.

22. Trichopoulou A, Lagiou P, Kuper H, Trichopoulos D. Cancer and Mediterranean dietary traditions. Cancer Epidemiol Biomarkers Prev. 2000; 9:869-73.

23. Pelucchi C, Bosetti C, Negri E, et al. Olive Oil and Cancer Risk: an Update of Epidemiological Findings through 2010. Curr Pharm Des. $2011 ; 17: 805-12$

24. Gathirua-Mwangi WG, Zhang J. Dietary factors and risk for advanced prostate cancer. Eur J Cancer Prev. 2014; 23:96-109.

25. Granados S, Quiles JL, Gil A, Ramírez-Tortosa MC. Dietary lipids and cancer. Nutr Hosp. 2006; 21 Suppl 2:42-52, 44-54.

26. Bairati I, Meyer F, Fradet Y, Moore L. Dietary fat and advanced prostate cancer. J Urol. 1998; 159:1271-5.

27. Szymanski KM, Wheeler DC, Mucci LA. Fish consumption and prostate cancer risk: A review and meta-analysis. Am J Clin Nutr. 2010; 92:1223-33.

28. Aune D, De Stefani E, Ronco A, et al. Legume intake and the risk of cancer: A multisite case-control study in Uruguay. Cancer Causes Control. 2009; 20:1605-15.

29. Mehdad A, McBride E, Grillo IM, et al. Nutritional status and eating pattern in prostate cancer patients. Nutr Hosp. 2010; 25:422-7. 
30. Bosire C, Stampfer MJ, Subar AF, et al. Index-based dietary patterns and the risk of prostate cancer in the NIH-AARP diet and health study. Am J Epidemiol. 2013; 177:504-13.

31. Key TJ. Nutrition, hormones and prostate cancer risk: Results from the European prospective investigation into cancer and nutrition. Recent Results Cancer Res. 2014; 202:39-46.

32. Rizos C, Papassava M, Golias C, Charalabopoulos K. Alcohol consumption and prostate cancer: A mini review. Exp Oncol. 2010; 32:6670.

33. Russo GI, Campisi D, Mauro M, et al. Dietary consumption of phenolic acids and prostate cancer: A case-control study in sicily, Southern Italy. Molecules. 2017; 22. pii: E2159.

34. Litman HJ, McKinlay JB. The future magnitude of urological symptoms in the USA: Projections using the Boston Area Community Health survey. BJU Int. 2007; 100:820-5.

35. Suzuki S, Platz EA, Kawachi I, et al. Intakes of energy and macronutrients and the risk of benign prostatic hyperplasia. Am J Clin Nutr. 2002; 75:689-97.

36. Lagiou P, Wuu J, Trichopoulou A, et al. Diet and benign prostatic hyperplasia: A study in Greece. Urology. 1999; 54:284-90.

37. Vignozzi L, Morelli A, Sarchielli E, et al. Testosterone protects from metabolic syndrome-associated prostate inflammation: An experimental study in rabbit. J Endocrinol. 2012; 212:71-84.

38. Kristal AR, Arnold KB, Schenk JM, et al. Dietary patterns, supplement use, and the risk of symptomatic benign prostatic hyperplasia: Results from the Prostate Cancer Prevention Trial. Am J Epidemiol. 2008; 167:925-34.

39. Schwarz S, Obermüller-Jevic UC, Hellmis E, et al. Lycopene inhibits disease progression in patients with benign prostate hyperplasia. J Nutr. 2008; 138:49-53.

40. Liao S. The medicinal action of androgens and green tea epigallocatechin gallate. Hong Kong Med J. 2001; 7:369-7.

41. Li XM, Zhang L, Li J, et al. Measurement of serum zinc improves prostate cancer detection efficiency in patients with PSA levels between $4 \mathrm{ng} / \mathrm{mL}$ and $10 \mathrm{ng} / \mathrm{mL}$. Asian J Androl. 2005; 7:323-8.

42. Gómez Y, Arocha F, Espinoza F, et al. Zinc levels in prostatic fluid of patients with prostate pathologies. Invest Clin. 2007; 48:287-94.

43. Leitzmann MF, Stampfer MJ, Wu K, et al. Zinc supplement use and risk of prostate cancer. J Natl Cancer Inst. 2003; 95:1004-7.

44. Chyou PH, Nomura AMY, Stemmermann GN, Hankin JH. A prospective study of alcohol, diet, and other lifestyle factors in relation to obstructive uropathy. Prostate. 1993; 22:253-64.

45. Lopatkin NA, Apolikhin OI, Sivkov AV, et al. Results of a multicenter trial of serenoa repens extract in patients with chronic abacterial prostatitis. Urologiia. 2007; 5:3-7.

46. Giulianelli R, Pecoraro S, Sepe G, et al. Multicentre study on the efficacy and tolerability of an extract of Serenoa repens in patients with chronic benign prostate conditions associated with inflammation. Arch Ital Urol Androl. 2012; 84:94-8.

47. Sinescu I, Geavlete P, Multescu R, et al. Long-term efficacy of Serenoa repens treatment in patients with mild and moderate symptomatic benign prostatic hyperplasia. Urol Int. 2011; 86:284-9.

48. Gerber GS, Kuznetsov D, Johnson BC, Burstein JD. Randomized, double-blind, placebo-controlled trial of saw palmetto in men with lower urinary tract symptoms. Urology. 2001; 58:960-4.

49. Helfand BT, Lee JY, Sharp V, et al. CAMUS Study Group. Associations between improvements in lower urinary tract symptoms and sleep disturbance over time in the CAMUS trial. J Urol. 2012; 188:2288-93

50. Dedhia RC, McVary KT. Phytotherapy for lower urinary tract symptoms secondary to benign prostatic hyperplasia. J Urol. 2008; 179:2119-2125.

51. Bent S, Kane C, Shinohara K, et al. Saw palmetto for benign prostatic hyperplasia. N Engl J Med. 2006; 354:557-566.

52. Ye Z, Huang J, Zhou L, et al. Efficacy and safety of Serenoa repens extract among patients with benign prostatic hyperplasia in China: a multicenter, randomized, double-blind, placebo-controlled trial. Urology. 2019; 129:172-179.

53. Barry MJ, Meleth S, Lee JY, et al. Complementary and Alternative Medicine for Urological Symptoms (CAMUS) Study Group. Effect of increasing doses of saw palmetto extract on lower urinary tract symptoms: a randomized trial. JAMA. 2011; 306:1344-51.

54. Giannakopoulos X, Baltogiannis D, Giannakis D, et al. The lipidosterolic extract of Serenoa repens in the treatment of benign prostatic hyperplasia: a comparison of two dosage regimens. Adv Ther. 2002; 19:285-96.

55. Alcaraz A, Carballido-Rodríguez J, Unda-Urzaiz M, et al. Quality of life in patients with lower urinary tract symptoms associated with BPH: change over time in real-life practice according to treatment--the QUALIPROST study. Int Urol Nephrol. 2016; 48:645-56.

56. Pytel YA, Lopatkin NA, Gorilovski LM, et al. The results of longterm permixon treatment in patients with symptoms of lower urinary tracts dysfunction due to benign prostatic hyperplasia. Urologia. 2004; 2:3-7.

57. Pytel YA, Vinarov A, Lopatkin N, et al. Long-term clinical and biologic effects of the lipidosterolic extract of Serenoa repens in patients with symptomatic benign prostatic hyperplasia. Adv Ther. 2002; 19:297-306.

58. Debruyne F, Koch G, Boyle P, et al. (Groupe d'étude PERMAL). Comparison of a phytotherapeutic agent (Permixon) with an alpha blocker (Tamsulosin) in the treatment of benign prostatic hyperplasia: A 1 - year randomized international study. Prog Urol. 2002; 12:384-92. 59. Cai T, Morgia G, Carrieri G, et al. IDIProst ${ }^{\circledR}$ Gold Study Group. An improvement in sexual function is related to better quality of life, regardless of urinary function improvement: results from the IDIProst ${ }^{\circledR}$ Gold Study. Arch Ital Urol Androl. 2013; 85:184-9.

60. Morgia G, Mucciardi G, Gali A, et al. Treatment of chronic prostatitis/chronic pelvic pain syndrome category IIIA with Serenoa repens plus selenium and lycopene (Profluss) versus S. repens alone: an Italian randomized multicenter - controlled study. Urol Int. 2010; 84:400-6.

61. Morgia G, Russo GI, Voce S, et al. Serenoa repens, lycopene and selenium versus tamsulosin for the treatment of LUTS/BPH. An Italian multicenter double-blinded randomized study between single or combination therapy (PROCOMB trial). Prostate. 2014; 74:1471-80.

62. Boeri L, Capogrosso P, Ventimiglia E, et al. Clinically meaningful Improvements in LUTS/BPH severity in men treated with silodosin plus xexanic extract of Serenoa repens or silodosin alone. Sci Rep. 2017; 7:15179.

63. Ryu YW, Lim SW, Kim JH, et al. Comparison of tamsulosin plus serenoa repens with tamsulosin in the treatment of benign prostatic hyperplasia in Korean men: 1-year randomized open label study. Urol Int. 2015; 94:187-93.

64. Argirovic A, Argirovic D. Does the addition of Serenoa repens to tamsulosin improve its therapeutical efficacy in benign prostatic hyperplasia? Vojnosanit Pregl. 2013; 70:1091-6.

65. Glemain P, Coulange C, Billebaud T, et al. Groupe de l'essai OCOS. Tamsulosin with or without Serenoa repens in benign prostatic hyperplasia: the OCOS trial. Prog Urol. 2002; 12:395-403.

66. Hizli F, Uygur MC. A prospective study of the efficacy of Serenoa repens, tamsulosin, and Serenoa repens plus tamsulosin treatment for patients with benign prostate hyperplasia. Int Urol Nephrol. 2007; 39:879-86. 
67. Bertaccini A, Giampaoli M, Cividini R, et al. Observational database serenoa repens (DOSSER): overview, analysis and results. A multicentric SIUrO (Italian Society of Oncological Urology) project. Arch Ital Urol Androl. 2012; 84:117-22.

68. Boyle P, Robertson C, Lowe F, Roehrborn C. Updated meta - analysis of clinical trials of Serenoa repens extract in the treatment of symptomatic benign prostatic hyperplasia. BJU Int. 2004; 93:751-756.

69. Wilt T, Ishani A, Mac Donald R. Serenoa repens for benign prostatic hyperplasia. Cochrane Database Syst Rev. 2002; 3:CD001423.

70. Vela-Navarrete R, Alcaraz A, Rodríguez-Antolin A, et al. Efficacy and safety of a hexanic extract of Serenoa repens $\left(\right.$ Permixon $\left.^{\circledR}\right)$ for the treatment of lower urinary tract symptoms associated with benign prostatic hyperplasia (LUTS/BPH): systematic review and meta-analysis of randomised controlled trials and observational studies. BJU Int. 2018; 122:1049-1065.

71. Tacklind J, MacDonald R, Rutks I, Wilt TJ. Serenoa repens for benign prostatic hyperplasia. Cochrane Database Syst Rev 2009; 2:CD001423

72. Squadrito F, Morgia G. The association of Serenoa repens, Lycopene and Selenium is superior to Serenoa repens alone in reducing benign prostatic hyperplasia. Urologia 2011;78:297-9.

73. Safarinejad MR. Urtica dioica for treatment of benign prostatic hyperplasia: a prospective, randomized, double-blind, placebo-controlled, crossover study. J Herb Pharmacother. 2005; 5:1-11.

74. Pavone C, Abbadessa D, Tarantino ML, et al. Associating Serenoa repens, Urtica dioica and Pinus pinaster. Safety and efficacy in the treatment of lower urinary tract symptoms. Prospective study on 320 patients. Urologia. 2010; 77:43-51.

75. Lopatkin N, Sivkov A, Walther C, et al. Long-term efficacy and safety of a combination of sabal and urtica extract for lower urinary tract symptoms--a placebo-controlled, double-blind, multicenter trial. World J Urol. 2005; 23:139-46.

76. Lopatkin N, Sivkov A, Schla S, et al. Efficacy and safety of a combination of Sabal and Urtica extract in lower urinary tract symptoms - long-term followup of a placebo-controlled, double-blind, multicenter trial. Int Urol Nephrol. 2007; 39:1137-46.

77. Changping M, Meng W, Maimaiti A, et al. The efficacy and safety of urtica dioica in treating benign prostatic hyperplasia: a systematic review and meta-analysis. Afr J Tradit Complement Altern Med. 2016; 13:143-50.

78. Barlet A, Albrecht J, Aubert A, et al. Wirksamkeit eines extraktes aus Pygeum africanum in der medikamentosen therapie von miktionsstorungen infolge einer benignen prostatahyperplasie: bewertung objektiver und subjektiver parameter. Wien Klin Wochenschr. 1990; 102:667-73.

79. Barth H. Non hormonal treatment of benign prostatic hypertrophy. Clinical evaluation of the active extract of Pygeum africanum. Proceedings of Symposium on Benign Prostatic Hypertrophy; Paris, 1981; pp 45-8.

80. Wilt TJ, Ishani A. Pygeum africanum for benign prostatic hyperplasia. Cochrane Database of Systematic Reviews 1998; 1: CD001044.

81. Hong H, Kim CS, Maeng S. Effects of pumpkin seed oil and saw palmetto oil in Korean men with symptomatic benign prostatic hyperplasia. Nutr Res Pract. 2009; 3:323-7.

82. Friederich M, Theurer C, Schiebel-Schlosser G. Prosta Fink Forte capsules in the treatment of benign prostatic hyperplasia. Multicentric surveillance study in 2245 patients. Forsch Komplementarmed Klass Naturheilkd. 2000; 7:200-4.

83. Vahlensieck W, Theurer C, Pfitzer E, et al. Effects of pumpkin seed in men with lower urinary tract symptoms due to benign prostatic hyperplasia in the one-year, randomized, placebo-controlled GRANU study. Urol Int. 2015; 94:286-95.

84. Damiano R, Cai T, Fornara P, et al. The role of Cucurbita pepo in the management of patients affected by lower urinary tract symptoms due to benign prostatic hyperplasia: A narrative review. Arch Ital Urol Androl. 2016; 88:136-43.

85. Siler U, Herzog A, Spitzer V, et al. Wertz Lycopene effects on rat normal prostate and prostate tumor tissue. J Nutr. 2005; 135:2050S-2S.

86. Herzog A, Siler U, Spitzer V, et al. Lycopene reduced gene expression of steroid targets and inflammatory markers in normal rat prostate. FASEB J. 2005; 19:272-4.

87. Schwarz K, Foltz CM. Selenium as an integral part of factor 3 against dietary necrotic liver degeneration. Nutrition. 1999; 15:255.

88. Flohe L, Günzler WA, Schock HH. Glutathione peroxidase: a selenoenzyme. FEBS Lett. 1973; 32:132-4.

89. Rotruck JT, Pope AL, Ganther HE, et al. Selenium: biochemical role as a component of glutathione peroxidase. Science 1973;179:588-90.

90. Spallholz JE, Boylan LM, Larsen HS. Advances in understanding selenium's role in the immune system. Ann N Y Acad Sci. 1990; 587:123-39.

91. Bonvissuto G, Minutoli L, Morgia G, et al. Effect of Serenoa repens, lycopene, and selenium on proinflammatory IkB-alfa phenotype activation: an in vitro and in vivo comparison study. Urology. 2001; 77:248 e 9-16.

92. Altavilla D, Bitto A, Polito F, et al. The combination of Serenoa repens, selenium and lycopene is more effective than serenoa repens alone to prevent hormone dependent prostatic growth. J Urol. 2011; 186:1524-1529.

93. Minutoli L, Bitto A, Squadrito F, et al. Serenoa Repens, lycopene and selenium: a triple therapeutic approach to manage benign prostatic hyperplasia. Curr Med Chem. 2013; 20:1306-12.

94. Morgia G, Cimino S, Favilla V, et al. Effects of Serenoa repens, selenium and lycopene (Profluss ${ }^{\circledR}$ ) on chronic inflammation associated with benign prostatic hyperplasia: results of "FLOG" (Flogosis and Profluss in Prostatic and Genital Disease), a multicentre Italian study.Int Braz J Urol. 2013; 39:214-21.

95. Coulson S, Rao A, Beck SL, et al. A phase II randomised doubleblind placebo-controlled clinical trial investigating the efficacy and safety of ProstateEZE Max: a herbal medicine preparation for the management of symptoms of benign prostatic hypertrophy. Complement Ther Med. 2013; 21:172-9.

96. Anderson ML. A preliminary investigation of the enzymatic inhibition of 5alpha-reduction and growth of prostatic carcinoma cell line LNCap-FGC by natural astaxanthin and Saw Palmetto lipid extract in vitro J Herb Pharmacother. 2005; 5:17-26.

97. Kolenko V, Teper E, Kutikov A, Uzzo R. Zinc and zinc transporters in prostate carcinogenesis. Nat Rev Urol. 2013; 10:219-26.

98. Mohamad J, Masrudin SS, Alias Z, Muhamad NA. The effects of Pueraria mirifica extract, diadzein and genistein in testosteroneinduced prostate hyperplasia in male Sprague Dawley rats. Mol Biol Rep. 2019; 46:1855-1871.

99. Tiscione D, Gallelli L, Tamanini I, et al. Daidzein plus isolase associated with zinc improves clinical symptoms and quality of life in patients with LUTS due to benign prostatic hyperplasia: Results from a phase I-II study. Arch Ital Urol Androl. 2017; 89:12-16.

100. McConnell ID, Roehrborn CG, Bautista OM, et al. Medical Therapy of prostatic Symptoms (MTOPS) Research Group. The logterm effect of doxazosin, finasteride. and combination therapy on the clinical progression of benign prostatic hyperplasia. N Engl J Med. 2003; 349:2387-8928.

101. Nickel JC, Roehrborn CG, O'Leaery MP, et al. The relationship 
between prostate inflammation and lower urinary tract symptoms: examination of baseline data from the REDUCE trial. Eur Urol. 2008; 54:1379-8.

102. Hiipakka RA, Zhang HZ, Dai W, et al. Structure-activity relationships for inhibition of human 5alpha-reductases by polyphenols. Biochem Pharmacol. 2002; 63:1165-76.

103. Park JS, Yeom MH, Park WS, et al. Enzymatic hydrolysis of green tea seed extract and its activity on 5alpha-reductase inhibition. Biosci Biotechnol Biochem. 2006; 70:387-94.

104. Evans BA, Griffiths K, Morton MS. Inhibition of 5 alpha-reductase in genital skin fibroblasts and prostate tissue by dietary lignans and isoflavonoids. J Endocrinol. 1995; 147:295-302.

105. Bisson JF, Hidalgo S, Rozan P, Messaoudi M. Preventive effects of ACTICOA powder, a cocoa polyphenolic extract, on experimentally induced prostate hyperplasia in Wistar-Unilever rats. J Med Food. 2007; 10:622-7.

106. Yang A, Ren G, Tang L, Jiang W. Effects of soy bean isoflavone on inhibition of benign prostatic hyperplasia and the expressions of NO and NOS of rats Wei Sheng Yan Jiu. 2009; 38:172-4.

107. Borovskaya TG, Krivova NA, Zaeva OB, et al. Dihydroquercetin effects on the morphology and antioxidant/prooxidant balance of the prostate in rats with sulpiride-induced benign hyperplasia. Bull Exp Biol Med. 2015; 158:513-6.

108. Ma Z, Hung Nguyen T, Hoa Huynh T, et al. Reduction of rat prostate weight by combined quercetin-finasteride treatment is associated with cell cycle deregulation. J Endocrinol. 2004; 181:493-507.

109. Altavilla D, Minutoli L, Polito F, et al. Effects of flavocoxid, a dual inhibitor of COX and 5-lipoxygenase enzymes, on benign prostatic hyperplasia. Br J Pharmacol. 2012; 167:95-108.

110. Edwin DL. Anti-oxidant and anti-aging properties of equol in prostate health. Open J Endocr Metab Dis. 2014; 4:1-12.

111. Jang H, Ha US, Kim SJ, et al. Anthocyanin extracted from black soybean reduces prostate weight and promotes apoptosis in the prostatic hyperplasia-induced rat model. J Agric Food Chem. 2010; 58:12686-91.

112. Kalu WO, Okafor PN, Ijeh II, Eleazu C. Effect of kolaviron, a biflavanoid complex from Garcinia kola on some biochemical parameters in experimentally induced benign prostatic hyperplasic rats. Biomed Pharmacother. 2016; 83:1436-1443.

113. Chen J, Song H. Protective potential of epigallocatechin-3-gallate against benign prostatic hyperplasia in metabolic syndrome rats. Environ Toxicol Pharmacol. 2016; 45:315-20.

114. Ren GY, Chen CY, Chen WG, et al. The treatment effects of flaxseed-derived secoisolariciresinol diglycoside and its metabolite enterolactone on benign prostatic hyperplasia involve the G proteincoupled estrogen receptor 1. Appl Physiol Nutr Metab. 2016; 41:13031310.

115. Kim SK, Seok H, Park HJ, et al. Inhibitory effect of curcumin on testosterone induced benign prostatic hyperplasia rat model. BMC Complement Altern Med. 2015; 15:380.

116. Ghorbanibirgani A. Efficacy of quercetin in treatment of benign prostatic hyperplasia in a double-blind randomized clinical trial in Iran-2011. Contraception 2012; 85:321.

117. Lephart ED. Severe and moderate BPH symptoms in mid-aged men improved with isoflavonoid-equol treatment: pilot intervention study. Open J Urol. 2013; 3:21-27.

118. Wong WC, Wong EL, Li H, et al. Isoflavones in treating watchful waiting benign prostate hyperplasia: a double-blinded, randomized controlled trial. J Altern Complement Med. 2012; 18:54-60.

119. Ledda A, Belcaro G, Dugall M, et al. Meriva ${ }^{\circledR}$, a lecithinized curcumin delivery system, in the control of benign prostatic hyperplasia: a pilot, product evaluation registry study. Panminerva Med. 2012; 54(1 Suppl 4):17-22.

120. Kjaer TN, Ornstrup MJ, Poulsen MM, et al. Resveratrol reduces the levels of circulating androgen precursors but has no effect on, testosterone, dihydrotestosterone, PSA levels or prostate volume. A 4-month randomised trial in middle-aged men. Prostate. 2015; 75:1255-63.

121. Hevesi Tóth B, Blazics B, Kéry A. Polyphenol composition and antioxidant capacity of Epilobium species. J Pharm Biomed Anal. 2009; 49:26-31.

122. Ledda A, Belcaro G, Feragalli B, et al. Benign prostatic hypertrophy: Pycnogenol ${ }^{\circledR}$ supplementation improves prostate symptoms and residual bladder volume. Minerva Med. 2018; 109:280-284.

123. Locatelli M, Macchione N, Ferrante C, et al. Graminex pollen: phenolic pattern, Colorimetric analysis and protective effects in immortalized prostate cells (PC3) and rat prostate challenged with LPS. Molecules 2018; 23. pii: E1145.

124. Loschen G, Ebeling L. Inhibition of arachidonic acid cascade by extract of rye pollen. Arzneimittelforschung. 1991; 41:162-167.

125. Shahed AR, Shoskes DA. Correlation of beta-endorphin and prostaglandin E2 levels in prostatic fluid of patients with chronic prostatitis with diagnosis and treatment response. J Urol. 2001; 166:1738-41.

126. Habib FK, Ross M, Buck AC, et al. In vitro evaluation of the pollen extract, cernitin $\mathrm{T}-60$, in the regulation of prostate cell growth. $\mathrm{Br} \mathrm{J}$ Urol. 1990; 66:393-397.

127. Habib FK, Ross M, Lewenstein A, et al. Identification of a prostate inhibitory substance in a pollen extract. Prostate. 1995; 26:133-139.

128. Kamijo T, Sato S, Kitamura T. Effect of cernitin pollen-extract on experimental nonbacterial prostatitis in rats. Prostate. 2001; 49:122-131.

129. Talpur N, Echard B, Bagchi D, et al. Comparison of Saw palmetto (extract and whole berry) and cernitin on prostate growth in rats. Mol Cell Biochem. 2003; 250:21-26.

130. Nagashima A, Ishii M, Yoshinaga M, et al. Effect of cernitin extract (Cernilton) on the function of urinary bladder in conscious rats. Japan Pharmacol Ther. 1998; 26:51-56.

131. Cai T, Verze P, La Rocca R, et al. The role of flower pollen extract in managing patients affected by chronic prostatitis/chronic pelvic pain syndrome: a comprehensive analysis of all published clinical trials. BMC Urol. 2017; 17:32.

132. Buck AC, Rees RW, Ebeling L. Treatment of chronic prostatitis and prostatodynia with pollen extract. Br J Urol. 1989; 64:496-9.

133. Cai T, Luciani LG, Caola I, et al. Effects of pollen extract in association with vitamins $\left(D E P R O X 500^{\circledR}\right)$ for pain relief in patients affected by chronic prostatitis/chronic pelvic pain syndrome: results from a pilot study. Urologia. 2013; 80 Suppl 22:5-10.

134. Cai T, Wagenlehner FM, Luciani LG, et al. Pollen extract in association with vitamins provides early pain relief in patients affected by chronic prostatitis/chronic pelvic pain syndrome. Exp Ther Med. 2014; 8:1032-8

135. Elist J. Effects of pollen extract preparation prostat/poltit on lower urinary tract symptoms in patients with chronic nonbacterial prostatitis/chronic pelvic pain syndrome: a randomized, double-blind, placebocontrolled study. Urology. 2006; 67:60-3.

136. Iwamura H, Koie T, Soma O, et al. Eviprostat has an identical effect compared to pollen extract (Cernilton) in patients with chronic prostatitis/chronic pelvic pain syndrome: a randomized, prospective study. BMC Urol. 2015; 15:120.

137. Jodai A, Maruta N, Shimomae E, et al long-term therapeutic 
experience with cernilton in chronic prostatitis. Hinyokika Kiyo. 1988; 34:561-8

138. Monden K, Tsugawa M, Ninomiya $Y$, et al. A Japanese version of the national institutes of health chronic prostatitis symptom index (NIHCPSI, Okayama version) and the clinical evaluation of cernitin pollen extract for chronic non-bacterial prostatitis. Nihon Hinyokika Gakkai Zasshi. 2002; 93:539-47.

139. Rugendorff EW, Weidner W, Ebeling L, et al. Results of treatment with pollen extract (Cernilton $N$ ) in chronic prostatitis and prostatodynia. Br J Urol. 1993; 71:433-8.

140. Suzuki T, Kurokawa K, Mashimo T, et al. Clinical effect of cernilton in chronic prostatitis. Hinyokika Kiyo. 1992; 38:489-94.

141. Wagenlehner FM, Schneider H, Ludwig M, et al. A pollen extract (Cernilton) in patients with inflammatory chronic prostatitis-chronic pelvic pain syndrome: a multicentre, randomised, prospective, doubleblind, placebo-controlled phase 3 study. Eur Urol. 2009; 56:544-51.

142. Bin Sayeed MS, Karim SMR, Sharmin T, Morshed MM. Critical analysis on characterization, systemic effect, and therapeutic potential of beta-sitosterol: a plant-derived orphan phytosterol. Medicines (Basel). 2016; 3(4).pii: E29.

143. Wilt T, Ishani A, MacDonald R, et al. Beta-sitosterols for benign prostatic hyperplasia. Cochrane Database Syst Rev. 2000; (2):CD001043.

144. Costa B, Comelli F, Bettoni I, et al. The endogenous fatty acid amide, palmitoylethanolamide, has anti-allodynic and anti-hyperalgesic effects in a murine model of neuropathic pain: involvement of $C B$ (1), TRPV1 and PPARgamma receptors and neurotrophic factors. Pain. 2008; 139:541-50.

145. Conti S, Costa B, Colleoni M, et al. Antinflammatory action of endocannabinoid palmitoylethanolamide and the synthetic cannabinoid nabilone in a model of acute inflammation in the rat. $\mathrm{Br} J$ Pharmacol. 2002; 135:181-7.

146. Cordaro M, Impellizzeri D, Siracusa R, et al. Effects of a comicronized composite containing palmitoylethanolamide and polydatin in an experimental model of benign prostatic hyperplasia. Toxicol Appl Pharmacol. 2017; 329:231-240.

147. Fei X, Shen Y, Li X, Guo H. The association of tea consumption and the risk and progression of prostate cancer: a meta-analysis. Int $J$ Clin Exp Med. 2014; 7:3881-91.

148. Lassed S, Deus CM, Lourenço N, et al. Diet, lifestyles, family history, and prostate cancer incidence in an East Algerian patient group. Biomed Res Int. 2016; 2016:5730569.

149. Sen A, Papadimitriou N, Lagiou P, et al. Coffee and tea consumption and risk of prostate cancer in the European Prospective Investigation into Cancer and Nutrition. Int J Cancer. 2019; 144:240250.

150. Perletti G, Magri V, Vral A, et al. Green tea catechins for chemoprevention of prostate cancer in patients with histologically-proven HG-PIN or ASAP. Arch Ital Urol Androl. 2019; 91:153-156.

151. Ilic D, Misso M. Lycopene for the prevention and treatment of benign prostatic hyperplasia and prostate cancer: a systematic review. Maturitas. 2012; 72:269-76.

152. Chen J, Song Y, Zhang L. Lycopene/tomato consumption and the risk of prostate cancer: a systematic review and meta-analysis of prospective studies. J Nutr Sci Vitaminol (Tokyo). 2013; 59:213-23.

153. Gann PH, Ma J, Giovannucci E, et al. Lower prostate cancer risk in men with elevated plasma lycopene levels: results of a prospective analysis. Cancer Res. 1999; 59:1225-30.

154. Paur I, Lilleby W, Bøhn SK, et al. Tomato-based randomized controlled trial in prostate cancer patients: Effect on PSA. Clin Nutr. 2017; 36:672-679.
155. Pantuck AJ, Leppert JT, Zomorodian N, et al. Phase II study of pomegranate juice for men with rising prostate-specific antigen following surgery or radiation for prostate cancer. Clin Cancer Res. 2006; 12:4018-26.

156. Pantuck AJ, Pettaway CA, Dreicer R, et al. A randomized, double-blind, placebo-controlled study of the effects of pomegranate extract on rising PSA levels in men following primary therapy for prostate cancer. Prostate Cancer Prostatic Dis. 2015; 18:242-8.

157. Stenner-Liewen F, Liewen H, Cathomas R, et al. Daily pomegranate intake has no impact on PSA levels in patients with advanced prostate cancer - Results of a phase IIb randomized controlled trial. J Cancer. 2013; 4:597-605.

158. deVere White RW, Tsodikov A, Stapp EC, et al. Effects of a high dose, aglycone-rich soy extract on prostate-specific antigen and serum isoflavone concentrations in men with localized prostate cancer. Nutr Cancer. 2010; 62:1036-43

159. He J, Wang S, Zhou M, et al. Phytoestrogens and risk of prostate cancer: a meta-analysis of observational studies. World J Surg Oncol. 2015; 13:231.

160. Perez-Cornago A, Appleby PN, Boeing H, et al. Circulating isoflavone and lignan concentrations and prostate cancer risk: a metaanalysis of individual participant data from seven prospective studies including 2,828 cases and 5,593 controls. Int J Cancer. 2018; 143:2677-268.

\section{Correspondence}

Arrigo F.G. Cicero, MD

arrigo.cicero@unibo.it

Dip. di Scienze Mediche e Chirurgiche, Alma Mater Studiorum,

Università di Bologna

Presidente Società Italiana di Nutraceutica

Olta Allkanjari, MD

olta.allkanjari@uniromal.it

Annabella Vitalone, $\mathrm{PhD}$

annabella.vitalone@uniromal.it

Dept. of Physiology and Pharmacology "V. Erspamer", Sapienza,

University of Rome, (Rome, Italy)

Gian Maria Busetto, MD

gianmaria.busetto@uniromal.it

Sapienza Università di Roma, Policlinico Umberto I, Roma (Italy)

Tommaso Cai, MD

ktommy@libero.it

Department of Urology, Santa Chiara Regional Hospital, Trento (Italy)

Gaetano Larganà, MD

Giorgio Ivan Russo, MD

giorgioivan1987@gmail.com

Urology Section, University of Catania, Catania (Italy)

Vittorio Magri, MD

vittorio.magri@virgilio.it

Ambulatorio Territoriale di Urologia ed Ecografia Urologica

ASST Nord Milano, Milano (Italy)

Gianpaolo Perletti, PhD

gianpaolo.perletti@uninsubria.it

Dipertimento di Biotecnologie e Scienze della Vita, Sezione di Scienze Mediche

e Chirurgiche, Università degli Studi dell'Insubria, Busto Arsizio (VA), (Italy)

Francesco Saverio Robustelli Della Cuna, PhD

fsaveriorobustelli@unipv.it

Department of Drugs Sciences, University of Pavia, Pavia (Italy)

Kostantinos Stamatiou

stamatiouk@gmail.com

Urology Dpt, Tzaneion Hospital, Piraeus (Greece)

Alberto Trinchieri, MD (Corresponding Author)

alberto.trinchieri@gmail.com

CDC Ambrosiana Milano 